\title{
Suscetibilidade a desinfetantes e perfil de resistência a antimicrobianos em isolados de Escherichia coli $^{1}$
}

\author{
Carina C. Krewer ${ }^{2}$, Letícia T. Gressler ${ }^{3}$, Mateus M. Costa ${ }^{2 *}$, Cristina C. Krewer ${ }^{2}$ \\ e Agueda C. Vargas ${ }^{3}$
}

\begin{abstract}
Krewer Ca.C., Gressler L.T., Costa M.M., Krewer Cr.C. \& Vargas A.C. 2012. [Susceptibility to disinfectants and antimicrobial resistance profile in Escherichia coli isolates.] Suscetibilidade a desinfetantes e perfil de resistência a antimicrobianos em isolados de Escherichia coli. Pesquisa Veterinária Brasileira 32(11):1116-1120. Laboratório de Microbiologia e Imunologia Animal, Universidade Federal do Vale do São Francisco, Rodov. BR 407 Km 12, Lote 543, Projeto de Irrigação Nilo Coelho s/n C1, Petrolina, PE 56300-000, Brazil. E-mail: mateus.costa@univasf.edu.br

Colibacillosis caused by Escherichia coli is the most important enteric disease in pig production, which may lead to death of the affected animal. The bacterium has a great ability to develop resistance to multiple antibiotics and disinfectants. Thus, investigation addressing mechanisms of resistance and profile of field samples is necessary. E. coli is widely used as a model for studies that explore the intrinsic and extrinsic resistance to multidrugs. In this paper, we attempt to associate the susceptibility profile of 62 isolates of $E$. coli to three disinfectants and 13 antimicrobials. Also 31 isolates were tested for the presence of efflux mechanism. Of the three disinfectants tested, alkyldimethylbenzylammonium chloride+nonyl phenoxy polyethoxy ethanol was the most effective (100\%), followed by glutaraldehyde+al kyldimethylbenzylammonium chloride (95.2\%) and alkyldimethylbenzylammonium chloride (88.8\%). Among the antimicrobials tested, there was greater resistance to tetracycline $(62.2 \%)$ and higher sensitivity to florfenicol $(88.6 \%)$. The high sensitivity of the isolates against disinfectants may be related to the absence of efflux mechanism. The average index of multiple resistance to antimicrobials was 0.52 , what demonstrates a profile of multidrug resistant isolates, showing the need for rational use of these drugs in pig production.
\end{abstract}

INDEX TERMS: Swine, Escherichia coli, resistance, disinfectants, efflux pump.

RESUMO.- A colibacilose, causada por Escherichia coli, é a enfermidade entérica de maior impacto na produção de suínos, podendo levar à morte do animal. Esta bactéria possui grande capacidade de desenvolver resistência a múltiplos antimicrobianos e a desinfetantes. Desta forma, estudos que abordem mecanismos de resistência e perfil de amostras de campo tornam-se necessários. E. coli é amplamente utilizada como modelo de estudos que exploram a resistência intrínseca e extrínseca a multidrogas. Neste trabalho, buscou-se

\footnotetext{
${ }^{1}$ Recebido em 11 de abril de 2012.

Aceito para publicação em 6 de agosto de 2012.

${ }^{2}$ Laboratório de Microbiologia e Imunologia Animal, Universidade Federal do Vale do São Francisco (Univasf), Rodovia BR 407 Km 12, Lote 543, Projeto de Irrigação Nilo Coelho s/n C1, Petrolina, PE 56300-000, Brasil. *Autor para correspondência: mateus.costa@univasf.edu.br

${ }^{3}$ Departamento de Medicina Veterinária Preventiva, Universidade Federal de Santa Maria (UFSM), Avenida Roraima 1000, Camobi, Santa Maria, RS 97105-900, Brasil.
}

verificar o perfil de sensibilidade de 62 isolados de E. coli de suínos frente a três desinfetantes e a 13 antimicrobianos. Ainda, em 31 destes isolados foi pesquisada a presença de mecanismo de efluxo. Dos três desinfetantes avaliados, o cloreto de alquil dimetil benzil amônio+poliexietilenonil fenileter foi o que se mostrou mais eficaz (100\%), seguido do glutaraldeído+cloreto de alquil dimetil benzil amônio $(95,2 \%)$ e do cloreto de alquil dimetil benzil amônio $(88,8 \%)$. Dentre os antimicrobianos testados, observou-se maior resistência para a tetraciclina $(62,2 \%)$ e maior sensibilidade para o florfenicol (88,6\%). A alta sensibilidade dos isolados frente aos desinfetantes pode estar relacionada à ausência de mecanismo de efluxo. 0 índice de resistência múltipla médio aos antimicrobianos foi de 0,52 , o que demonstra um perfil multirresistente dos isolados, conduzindo para a necessidade do uso racional destas drogas em suinocultura.

TERMOS DE INDEXAÇÃO: Suínos, Escherichia coli, resistência, desinfetantes, bomba de efluxo. 


\section{INTRODUÇÃO}

A suinocultura é uma atividade de grande importância para a economia mundial, sendo o Brasil o quarto país em produção e o sexto em consumo de produtos derivados de suínos (Abipecs 2010). A colibacilose é a enfermidade entérica de maior impacto na produção de suínos, particularmente para animais neonatos e em pós-desmame (Henton $\&$ Hunter 1994). Ela pode ser ocasionada por dois patotipos, Escherichia coli enterotoxigênica (ETEC) e E. coli verotoxigênica (VTEC). A ETEC após aderir à mucosa intestinal e produzir enterotoxinas (STa, STb ou LT), causa diarréia e desidratação, podendo resultar na morte dos animais. Já a VTEC produz exotoxinas (shiga toxinas), as quais causam lesão nas células endoteliais, induzindo o aparecimento de edema e sinais nervosos, principalmente em leitões recémdesmamados (Henton \& Hunter 1994).

$E$. coli é uma das espécies nas quais cepas multirresistentes aos antimicrobianos têm emergido rapidamente, devido à sua grande distribuição ambiental e propensão a albergar elementos genéticos móveis, em especial os plasmídeos (Sherley et al. 2004). A utilização de antimicrobianos para o controle e profilaxia de enfermidades em suínos é amplamente difundida (Barcellos \& Sobestiansky 1998). 0 uso abusivo destas drogas agrava o desenvolvimento da resistência bacteriana, sendo esta cada vez mais evidente tanto em patógenos de origem humana, quanto animal (Wallmann 2006), dificultando o tratamento das infecções por estes agentes (Tikhonova et al. 2009). Além disso, a presença de resíduos de antibióticos nos alimentos de origem animal e a seleção de cepas resistentes representam sérios riscos à saúde pública (Barcellos \& Sobestiansky 1998).

A limpeza e a desinfecção do ambiente estão entre as principais medidas aplicáveis para prevenir enfermidades como a colibacilose, e reduzir a presença de micro-organismos no ambiente. Diversos produtos estão disponíveis no mercado, sendo os mais utilizados na suinocultura os compostos químicos à base de amônia quaternária, glutaraldeído e hipoclorito (Kich et al. 2004). Alguns trabalhos têm avaliado a atividade antibacteriana in vitro de diferentes desinfetantes frente a micro-organismos isolados de suínos e aves, como E. coli, Salmonella Typhimurium e Salmonella Enteritidis (Cardoso 2000, Sander et al. 2002, Borowsky et al. 2006), tendo em vista a importância da escolha correta do composto a ser utilizado em programas de controle sanitário.

A resistência bacteriana não deve ser atribuída apenas ao uso de antimicrobianos, já que desinfetantes e suplementos alimentares podem também apresentar considerável pressão de seleção em comunidades bacterianas presentes em criatórios de suínos. 0 mecanismo de efluxo de drogas tem sido destacado como um importante processo associado à resistência, principalmente em bactérias Gram negativas. Existem três proteínas responsáveis pelo mecanismo: uma proteína de membrana externa que atua como um canal durante o transporte, uma proteína da membrana interna que traduz energia eletroquímica de prótons em vetor de deslocamento dos compostos transportados e um componente periplásmico de transição, que liga as proteínas da membrana interna e externa (Pietras et al. 2008). Sabe-se que a resistência a compostos à base de amônia quaternária em E. coli está ligada à superexpressão de proteínas de transporte, ocorrendo assim intenso efluxo de substâncias através da membrana celular (Shahcheraghi et al. 2007, Takenaka et al. 2007).

A crescente resistência de patógenos a drogas antimicrobianas e a desinfetantes utilizados na suinocultura indica a necessidade contínua de investigação científica para deteç̧ão e compreensão destes mecanismos. Nesse sentido, os objetivos deste trabalho foram determinar a suscetibilidade aos antimicrobianos, pesquisar a presença do mecanismo de efluxo e verificar as concentrações inibitórias e bactericidas mínimas (CIMs e CBMs) de desinfetantes à base de amônia quaternária e aldeído em isolados de $E$. coli provenientes de granjas suinícolas dos estados do Rio Grande do Sul e de Santa Catarina.

\section{MATERIAL E MÉTODOS}

Foram utilizados 62 isolados de E. coli provenientes de fezes de suínos coletadas em diferentes criatórios suinícolas nos estados do Rio Grande do Sul e de Santa Catarina e uma cepa padrão de E. coli ATCC 25922. Os isolados bacterianos foram mantidos liofilizados a $-20^{\circ} \mathrm{C}$ até o momento das análises. Para realização dos testes, as amostras foram transferidas para ágar MacConkey (Himedia Laboratories $®$ ) e incubadas a $37^{\circ} \mathrm{C}$ por 48 horas. Foram testados três compostos desinfetantes distintos, utilizados nas granjas de origem das amostras. A determinação da CIM e da CBM seguiu a metodologia de microdiluição em caldo, segundo o documento M7-A4 (CLSI 2006). As concentrações do desinfetante A (cloreto de alquil dimetil benzil amônio+poliexietilenonilfenile ter) variaram de $0,4 \mathrm{a} 40 \mu \mathrm{g} / \mathrm{mL}$; as do desinfetante B (cloreto de alquil dimetil benzil amônio) de 2,5 a $160 \mu \mathrm{g} / \mathrm{mL}$ e as do desinfetante C (glutaraldeído+cloreto de alquil dimetil benzil amônio) de $0,62 \mathrm{a} 40 \mu \mathrm{g} / \mathrm{mL}$. Essas concentrações seguiram as recomendadas pelos fabricantes para uso em instalações suinícolas e foram preparadas previamente pela diluição dos compostos desinfetantes em caldo Müeller Hinton (Himedia Laboratories $®$ ).

0 inóculo bacteriano $\left(5 \times 10^{4}\right.$ Unidades Formadoras de Colônias - UFC) foi adicionado em cada poço de uma microplaca contendo $200 \mu \mathrm{L}$ de caldo Müeller Hinton e o composto químico a ser testado em diferentes concentrações. Como controle negativo utilizou-se apenas Müeller Hinton e como controle positivo o caldo e o inóculo bacteriano, sendo os ensaios realizados em triplicata. As placas foram incubadas a $37^{\circ} \mathrm{C}$ por 24 horas. A CIM foi considerada a menor concentração do desinfetante em que não se evidenciou crescimento bacteriano pela observação da turvação do caldo. A CBM foi determinada através da semeadura de $10 \mu \mathrm{L}$ dos poços em que não se evidenciou crescimento bacteriano em placas de ágar MacConkey, as quais foram incubadas a $37^{\circ} \mathrm{C}$ por 24 horas.

0 perfil de suscetibilidade dos micro-organismos foi determinado por meio do método de difusão em disco Kirby-Bauer modificado (Bauer et al. 1966). As drogas antimicrobianas avaliadas foram: ampicilina (10ug), trimetoprim: sulfametoxazol (25ug), tetraciclina (30ug), amicacina (30ug), colistina (25ug), norfloxacina (10ug), florfenicol (30ug), enrofloxacina (5ug), cefalexina (30ug), trimetoprim (25ug), neomicina (30ug), cloranfenicol (30ug) e gentamicina (30ug). 0 índice de resistência múltipla aos antimicrobianos (IRMA) foi calculado conforme metodologia descrita por Krumperman (1983), sendo determinado pela relação entre o número de classes antimicrobianas para as quais a amostra foi 
resistente e o número total de diferentes classes antimicrobianas testadas.

Para verificação de resistência mediada pela bomba de efluxo, utilizou-se metodologia descrita por Bjorland et al. (2005). Foram selecionados 31 isolados, representativos do total, e semeados em ágar Müeller Hilton contendo brometo de etídeo $(0,5 \mu \mathrm{L} / \mathrm{mL})$. Após incubação das placas a $37^{\circ} \mathrm{C}$ por 24 horas, realizou-se a leitura sob luz ultravioleta. A ausência de mecanismo de efluxo foi observada em colônias que demonstraram fluorescência.

\section{RESULTADOS}

Dos 62 isolados testados, 88,8\% foram sensíveis ao desinfetante B, 95,2\% ao desinfetante C e 100\% ao desinfetante A nas concentrações recomendadas pelos fabricantes. A cepa padrão testada mostrou-se sensível a todos os agentes testados. A CIM e CBM dos desinfetantes obtidas para os isolados de E. coli podem ser observadas na Figura 1.
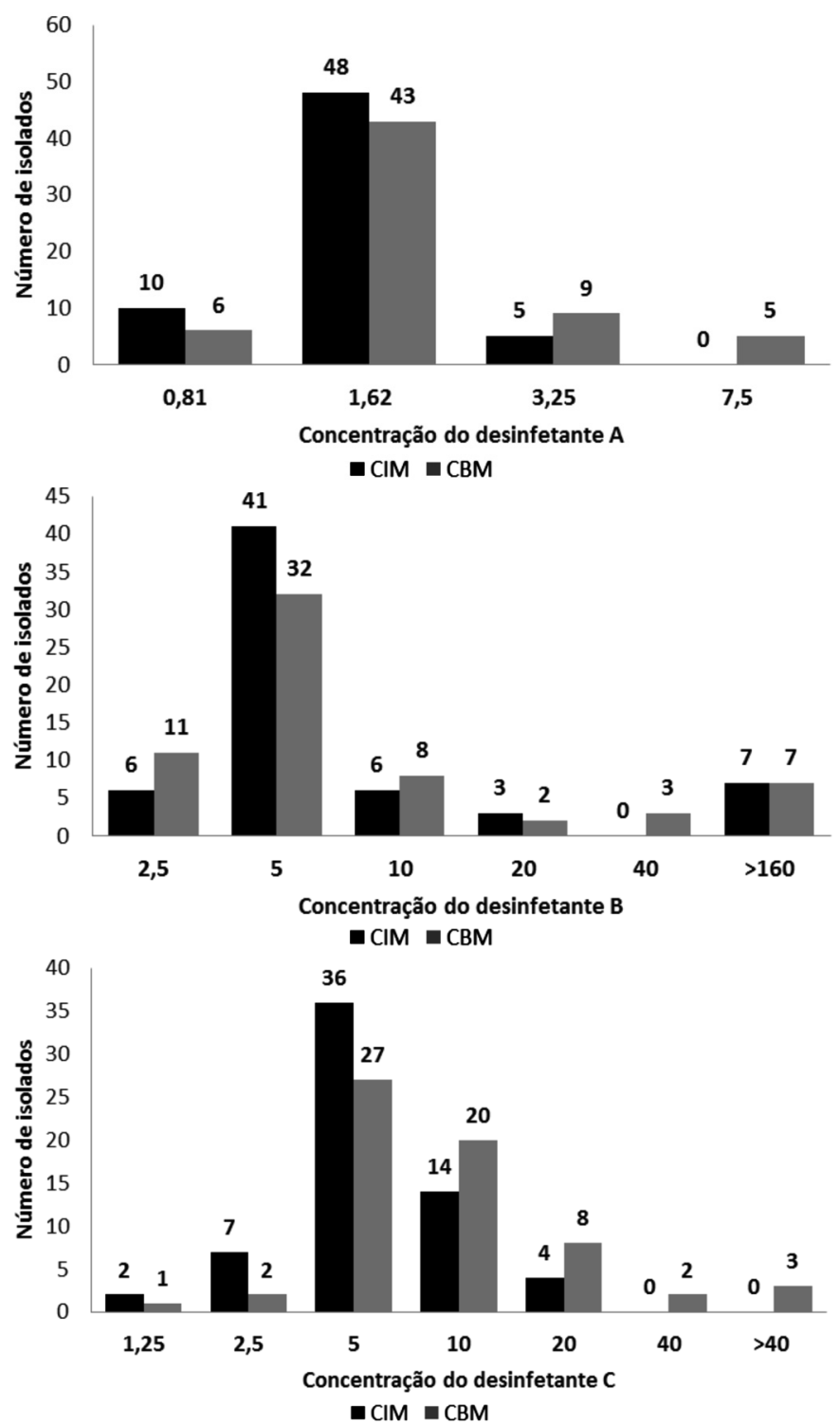

Fig.1. Concentração Inibitória Mínima (CIM) $(\mu \mathrm{g} / \mathrm{mL})$ e Concentração Bactericida Mínima (CBM) $(\mu \mathrm{g} / \mathrm{mL})$ de desinfetantes à base de aldeído e amônia quaternária frente a isolados de Escherichia coli provenientes de granjas suinícolas do Sul do Brasil.
Em relação à suscetibilidade aos antimicrobianos, o maior índice de resistência demonstrado pelos isolados foi para a tetraciclina (62,2\%). Entre as drogas avaliadas, o perfil de resistência foi de $11,4 \%$ para o florfenicol, seguido de cloranfenicol, 16,3\%, cefalexina, 27,8\%, colistina, $27,8 \%$, enrofloxacina, $29,5 \%$, trimetoprim, 31,1\%, norfloxacina, 34,4\%, neomicina, 36,0\%, ampicilina, 37,7\%, amicacina, 39,3\%, gentamicina, $40,9 \%$ e trimetoprim: sulfametoxazol, 49,1\%. O IRMA dos isolados avaliados variou de 0,11 a 1 com resultado médio de 0,52.

Ainda, nenhum dos 31 isolados de E. coli testados demonstrou a presença de mecanismo de efluxo por meio da metodologia utilizada.

\section{DISCUSSÃO}

No presente estudo, os isolados de E. coli apresentaram grande sensibilidade frente aos desinfetantes testados (Figura 1). Resultados semelhantes foram descritos por Borowsky et al. (2006) ao testarem 96 amostras de Salmonella spp., obtidas de matadouros, com compostos à base de amônia quaternária e iodofor.

Os desinfetantes avaliados neste trabalho representavam a combinação de compostos quaternários de amônio e glutaraldeído. 0 efeito sinérgico de compostos antimicrobianos tem sido associado ao maior sucesso no controle de bactérias, bem como, exerce uma menor pressão de seleção em populações microbianas (Harrison et al. 2008). Produtos à base de amônia quaternária e aldeídos são muito eficazes na desinfecção de ambientes contaminados por E. coli, o que foi comprovado no presente estudo, particularmente no que diz respeito ao desinfetante C. Entretanto, vários patógenos Gram negativos, em especial $E$. coli, são descritos como resistentes aos desinfetantes (Gilbert \& McBain 2003, Beier et al. 2005), uma vez que possuem a membrana externa da parede celular relativamente impermeável (Langsrud et al. 2004). Apesar disso, mutações nesta estrutura têm sido associadas a menor hidrofobicidade da membrana, o que facilita a ação destes agentes químicos (Kich et al. 2004).

Diversos autores relacionam a resistência bacteriana aos desinfetantes à presença de mecanismos como o efluxo de substâncias pelas células (Paixão et al. 2009, Kenneth et al. 2009, Srinivasan et al. 2009). Os resultados aqui encontrados reforçam esta hipótese, uma vez que os isolados mostraram-se muito sensíveis aos desinfetantes e o mecanismo de efluxo não foi observado. Em relação aos 11,2\% de cepas resistentes ao desinfetante $B$, acredita-se que outros mecanismos de resistência estejam envolvidos, como a produção de biofilmes, por exemplo. 0 composto poliexietilenonilfenileter presente no desinfetante $\mathrm{A}$, ao qual todas as amostras testadas foram sensíveis, caracteriza-se por sua ação tensoativa sendo muito eficaz na remoção do biofilme bacteriano (Kich et al. 2004).

A resistência às drogas antimicrobianas foi maior quando comparada aos compostos desinfetantes. De acordo com Krumperman (1983), consideram-se E. coli multirresistentes quando apresentam IRMA acima de 0,2. Neste estudo, a maioria dos isolados demonstraram índices acima de 0,52 , o que pode indicar potencial para transferência ho- 
rizontal de genes de resistência. Além disso, altos índices de resistência múltipla aos antimicrobianos representam risco para a saúde pública, dificultando o tratamento de enfermidades de animais e de humanos (Mota et al. 2005).

Segundo Russel (2002), desinfetantes e drogas antimicrobianas possuem diferentes mecanismos de ação para provocar a morte de micro-organismos, especialmente em bactérias Gram negativas e micobactérias, nas quais a impermeabilidade da parede celular é significativa. A sensibilidade das bactérias aos desinfetantes sempre é maior, uma vez que, devido ao seu uso ambiental, preconiza-se a aplicação destes em concentrações elevadas, dificultando a ação das bombas de efluxo (Thomas et al. 2000). Ainda, embora a co-resistência a antimicrobianos e a biocidas seja esperada (Langsrud et al. 2004), esta não tem sido observada para patógenos como $P$. aeruginosa, Salmonella spp. e E. coli (Hammond et al. 1987, Thomas et al. 2000, Sidhu et al. 2002).

Trabalho realizado por Kich et al. (2004), relacionando a suscetibilidade a antimicrobianos e a desinfetantes em Salmonella spp., demonstrou que a eficácia destes está mais relacionada à forma de uso do que com o perfil de resistência da bactéria. Estudos apontam que cepas Gram negativas multirresistentes não necessariamente são mais resistentes a desinfetantes do que as cepas antibiótico sensíveis, até mesmo quando genes de resistência à amônia quaternária estão presentes (Kucken et al. 2000). Estes dados confirmam os encontrados por Hammond et al. (1987), nos quais não foi possível traçar uma correlação consistente entre a presença de plasmídeos ou de resistência a antimicrobianos e a resistência a compostos desinfetantes.

Para os isolados avaliados no presente estudo, não foi possível estabelecer uma relação entre a elevada resistência aos antimicrobianos e a ausência de mecanismo de efluxo. Sabe-se, no entanto, que a resistência em E. coli e outros micro-organismos pode estar associada a diversos processos, como a modificação do composto antimicrobiano e de seu sítio de ação, além da formação de biofilmes (Nougayrède et al. 2003). A emergência de bactérias resistentes às drogas antimicrobianas e aos desinfetantes é preocupante, uma vez que esses patógenos podem determinar graves infecções no homem e nos animais. Nos últimos anos, o rodízio de compostos desinfetantes em programas sanitários tem se mostrado uma alternativa para redução da resistência microbiana. Para tal, produtos com diferentes princípios ativos devem ser utilizados (Russell 2002). Isto aponta para a importância dos dados obtidos neste trabalho, sendo que os compostos testados podem ser utilizados em programas de desinfecção pelas granjas suinícolas.

\section{CONCLUSÕES}

Para as amostras testadas, em relação aos três desinfetantes utilizados nos criatórios suínos, o desinfetante $\mathrm{A}$ apresenta-se mais eficaz, seguido do C e do B.

Não se evidenciou a resistência mediada pelo mecanismo de efluxo nos isolados testados, condizendo com o perfil de sensibilidade aos desinfetantes.

Dentre os antimicrobianos avaliados, observa-se maior resistência para a tetraciclina e maior sensibilidade ao florfenicol.

Por último, os resultados do IRMA demonstram um perfil multirresistente dos isolados, o que conduz para a necessidade do uso racional destas drogas em suinocultura.

\section{REFERÊNCIAS}

ABIPECS. Disponível em <http://www.abipecs.org.br> Acesso em 15 dez. 2011.

Barcellos D. \& Sobestiansky J. 1998. Uso de Antimicrobianos em Suinocultura. Goiânia. 107p.

Bauer A.W. 1966. Antibiotic susceptibility testing by a standardized single disk method. Am. J. Clin. Pathol. 45:493-496.

Beier R.C., Bischoff K.M., Ziprin R.L., Polle T.L. \& Nisbet T.J. 2005. Chlorhexidine susceptibility, virulence factors, and antibiotic resistance of beta-hemolytic Escherichia coli isolated from neonatal swine with diarrhea. Bull. Environ. Contam. Toxicol. 75:835-844.

Bjorland J., Steinum T., Kvitle B., Waage S., Sunde M. \& Heir E. 2005. Widespread distribution of disinfectant resistance genes among Staphylococci of bovine and caprine origin in Norway. J. Clin. Microbiol. 43:4363-4368.

Borowsky L.M., Bessa M.C., Cardoso M.I. \& Avancini C.A.M. 2006. Sensibilidade e resistência de amostras de Salmonella Typhimurium isoladas de suínos abatidos no Rio Grande do Sul/Brasil frente aos desinfetantes químicos quaternário de amônio e iodofor. Ciência Rural 36:76-79.

Cardoso M.O. 2000. Avaliação da sensibilidade a antimicrobianos e eficiência de desinfetantes em amostras de Salmonella Enteritidis isoladas de carcaças de frangos no estado do Rio Grande do Sul. Dissertação de Mestrado em Ciências Veterinárias, Universidade Federal do Rio Grande do Sul, Porto Alegre, RS. 108p.

CLSI 2006. Antimicrobial disk and dilution susceptibility tests for bacteria isolated from animals. Document M7-A4, Approved Standard. Clinical and Laboratory Standards Institute. $3^{\text {rd }}$ ed. Wayne. 53p.

Gilbert P. \& McBain A.J. 2003. Potential impact of increased use of biocides in consumer products on prevalence of antibiotic resistance. Clin. Microbiol. Rev. 16:189-208.

Hammond S.A., Morgan J.R. \& Russel A.D. 1987. Comparative susceptibility of hospital isolates of gram-negative bacteria to antiseptic and disinfectants. J. Hosp. Infect. 9:255-264.

Harrison J.J., Turner R.J., Joo D.A., Stan M.A., Chan C.S., Allan N.D., Vrionis H.A., Olson M.E. \& Ceri H. 2008. Copper and quaternary ammonium cations exert synergistic bactericidal and antibiofilm activity against $P$ seudomonas aeruginosa. Antimicrob. Agents Chemother. 52:2870-2881.

Henton M.M. \& Hunter P. 1994. E. coli infections, p.1085-1099. In: Coetzer J.A.W. \& Tustin R.C. (Eds.), Infectious Diseasesof Livestock. $5^{\text {th }}$ ed. Oxford University Press, New York.

Kich J.D., Borowsky L.M., Silva V.S., Ramenzoni M., Triques N., Kooler F.L. \& Cardoso M.R.I. 2004. Avaliação da atividade antibacteriana de seis desinfetantes comerciais frente a amostras de Salmonella Typhimurium isoladas de suínos. Acta Scient. Vet. 32:33-39.

Kenneth P.S., Kumar S. \& Varela M.F. 2009. Identification, cloning, and functional characterization ofemrd-3, aputative multidrug efflux pump of the major facilitatorsuperfamily from Vibrio Cholerae 0395. Arch. Microbiol. 191:903-911.

Krumperman P.H. 1983. Multiple antibiotic resistance indexing of Escherichia coli to identify high-risk sources of fecal contamination of foods. Appl. Environ. Microbiol. 46:165-170.

Kucken D., Feucht H. \& Kaulfers P. 2000. Association of qacE and qacEDelta1 with multiple resistance to antibiotics and antiseptics in clinical isolates of Gram negative bacteria. Fems Microbiol. Lett. 183:95-98.

Langsrud S., Sundheim G. \& Holck A.L. 2004. Cross-resistance to antibiotics of Escherichia coli adapted to benzalkonium chloride or exposed to stress-inducers. J. Appl. Microbiol. 96:201-208.

Mota R.A., Silva K.P.C., Freitas M.F.L., Porto W.J.N. \& Silva L.B.G. 2005. Utilização indiscriminada de antimicrobianos e sua contribuição a multirresitência bacteriana. Braz. J. Vet. Res. Anim. Sci. 42:465-470. 
Nougayrède J.P., Fernandes P. \& Donnenberg M.S. 2003. Adhesion of enteropathogenic Escherichia coli to host cells. Cell Microbiol. 5:359372.

Paixão L., Rodrigues L., Couto I., Martins M., Fernandes P., Carvalho C., Monteiro G.A., Sansonetty F., Amaral L. \& Viveiros M. 2009. Fluorometric determination of ethidium bromide efflux kinetics in Escherichia coli. J. Biomed. Eng. 3:3-18.

Pietras Z., Bavro V.N., Furnham N., Pellegrini-Calace M., Milner-White E.J. \& Luisi B.F. 2008. Structure and mechanism of drug efflux machinery in Gram negative bacteria. Curr. Drug. Targets 9:719-28.

Russell A.D. 2002. Mechanisms of antimicrobial action of antiseptics and disinfectants: an increasingly important area of investigation. J. Antimic. Chemoth. 49:597-599.

Sander J.E., Hofacre C.L., Cheng I. \& Wyatt R.D. 2002. Investigation of resistance of bacteria from commercial poultry sources to commercial disinfectants. Avian Dis. 46:997-1000.

Sidhu M.S., Sørum H. \& Holck A. 2002. Resistance to quaternary ammonium compounds in food-related bacteria. Microbial. Drug. Resistance. 8:393-399.

Srinivasan V.B., Rajamohan G. \& Gebreyes W.A. 2009. Role of AbeS, a novel efflux pump of the SMR family of transporters, in resistance to antimi- crobial agents in Acinetobacter baumannii. Antimic. Agents Chemoth. 53:5312-5316.

Shahcheraghi F., Minato Y., Chen J., Mizushima T., Ogawa W., Kuroda T. \& Tsuchiya T. 2007. Molecular cloning and characterization of a multidrug efflux pump, SmfY, from Serratia marcescens. Biol. Pharm. Bull. 30:798800.

Sherley M., Gordon D.M. \& Collignon P.J. 2004. Evolution of multi-resistance plasmids in Australian clinical isolates of Escherichia coli. Microbiol. 150:1539-1546.

Takenaka S., Tonoki T., Taira K., Murakami S. \& Aoki K. 2007. Adaptation of Pseudomonas sp. strain 7-6 to quaternary ammonium compounds and their degradation via dual pathways. Appl. Environ. Microbiol. 73:17971802.

Tikhonova E.B., Dastidar V., Rybenkov V.V. \& Zgurskaya H.I. 2009. Kinetic control of TolC recruitment by multidrug efflux complexes. Microbiol. 106:16416-16421.

Thomas L., Maillard J.Y., Lambert R.J. \& Russell A.D. 2000. Development of resistance to chlorhexidine diacetate in Pseudomonas aeruginosa and the effect of a "residual" concentration. J. Hosp. Infect. 46:297-303.

Wallmann J. 2006. Monitoring of antimicrobial resistence in pathogenic bacteria from livestock animals. Int. J. Med. Microbiol. 41:81-86. 